\title{
Corrosion and tribocorrosion behaviour of titanium nitride thin films grown on titanium under different deposition times
}

\author{
I. Çahaa,*, A.C. Alves ${ }^{a}$, L.J. Affonço ${ }^{\mathrm{b}, \mathrm{c}}$, P.N. Lisboa-Filho ${ }^{\mathrm{b}, \mathrm{c}}$, J.H.D. da Silva ${ }^{\mathrm{b}, \mathrm{c}}$, L.A. Rocha, ${ }^{\mathrm{a}, \mathrm{b}, \mathrm{c}}$, \\ A.M.P. Pinto ${ }^{\mathrm{a}, \mathrm{d}}$, F. Toptan ${ }^{\mathrm{a}, \mathrm{b}, \mathrm{d}}$ \\ ${ }^{\text {a }}$ CMEMS-Uminho - Center for MicroElectroMechanical Systems, Universidade do Minho, Azurém, 4800-058 Guimarães, Portugal \\ ${ }^{\mathrm{b}} \mathrm{IBTN} / \mathrm{Br}$ - Brazilan Branch of the Institute of Biomaterials, Tribocorrosion and Nanomedicine, Bauru, SP, Brazil \\ ${ }^{c}$ UNESP_Univ. Estadual Paulista, Faculdade de Ciências de Bauru, Dep. Física, 17033-360 Bauru, SP, Brazil \\ ${ }^{\mathrm{d}}$ Universidade do Minho, Dept. Eng. Mecânica, Azurém, 4800-058 Guimarães, Portugal
}

\section{A R T I C L E I N F O}

\section{Keywords:}

TiN

Corrosion

Tribocorrosion

\begin{abstract}
A B S T R A C T
Ti and its alloys exhibit combination of unique properties for biomedical applications, however their poor triboelectrochemical behaviour is a major concern. Therefore, TiN coatings were deposited on cp-Ti (grade 4) by sputtering technique aiming the improvement of its tribocorrosion behaviour. The properties of the coated samples, using different TiN deposition times, were characterized by using grazing incidence X-ray diffraction, FIB-SEM, and nanoindentation. The corrosion behaviour was studied by electrochemical impedance spectroscopy and potentiodynamic polarization in $9 \mathrm{~g} / \mathrm{L} \mathrm{NaCl}$ solution at body temperature. Tribocorrosion tests were employed under open circuit potential by using a ball-on-plate tribometer with $1 \mathrm{~N}$ normal load, $3 \mathrm{~mm}$ total stroke length, $1 \mathrm{~Hz}$ frequency, and $1800 \mathrm{~s}$ sliding duration. The results suggested that the TiN coatings deposited during 80 min presented better corrosion and tribocorrosion behaviour as compared to the bare metal and TiN coatings deposited during $30 \mathrm{~min}$.
\end{abstract}

\section{Introduction}

Titanium and its alloys are widely used in a variety of fields including chemical, automotive, aerospace, ocean engineering, and biomedical industries due to their high strength, low Young's modulus, excellent corrosion resistance, and biocompatibility [1-4]. However, one of the major disadvantages of $\mathrm{Ti}$ and its alloys is their poor tribological properties [5,6] raising a particular concern for biomedical load bearing implants since they are in contact with corrosive body fluids and being subjected to relative movements resulting in the subsequent release of metallic ions and wear debris to the body. In order to overcome the low tribological resistance of titanium and its alloys, several surface modification techniques have been applied such as organic and inorganic coatings [7], thermal oxidation [8], acid etching [9], electrochemical processes [10], plasma spraying [11] and laser nitriding [12]. On the other hand, physical vapour deposition (PVD), especially sputtering is an attractive method for coating biomedical implant surfaces with tailorable coating conditions giving properties such as high hardness, high corrosion resistance, chemical stability, biocompatibility, hemocompatibility, high wear and abrasion resistance [13-17]. Thus, TiN coatings have been tested on various implant materials such as dental implants, orthopaedic implants (hip, knee, ankle joint), cardiac and cardiovascular applications [18-21].

Although some studies are available on the corrosion and tribocorrosion behaviour of nitrided Ti or Ti alloy surfaces [10,22-28], investigations on the corrosion and tribocorrosion behaviour of TiN thin films sputtered on Ti surfaces are still scarce. Rizwan et al. [29] studied the electrochemical behaviour of nitrogen implanted cp-Ti in Ringer's lactate solution and found that the corrosion behaviour is improved as compared to untreated Ti. Savonov et al. [30] showed a better electrochemical behaviour of plasma immersed nitrogen implanted Ti-6Al$4 \mathrm{~V}$ alloy compared to the untreated alloy, as concluded from potentiodynamic polarization and electrochemical impedance spectroscopy tests in a $35 \mathrm{~g} / \mathrm{L} \mathrm{NaCl}$ solution at room temperature. El-Hossary et al. [31] observed an improved corrosion resistance of RF (radio frequency) plasma nitrided cp-Ti in Ringer's solution, as well, an enhancement on wear resistance after dry sliding were tests performed against $6 \mathrm{~mm}$ diameter alumina ball under a sliding speed of $2 \mathrm{~mm} / \mathrm{s}$ and a normal load of $1 \mathrm{~N}$. Pohrelyuk et al. [32] investigated the corrosion behaviour of nitrided Ti-6Al-4 V alloy in Ringer's solution at 36 and $40^{\circ} \mathrm{C}$ and indicated that nitrided alloy presented better behaviour, and also the corrosion resistance of Ti-6Al-4 V was decreased with

\footnotetext{
* Corresponding author.

E-mail address: id6757@alunos.uminho.pt (I. Çaha).
} 
increased solution temperature. Galliano et al. [22] studied the tribocorrosion behaviour of plasma nitrided Ti-6Al-4 V alloy treated at 700 and $900{ }^{\circ} \mathrm{C}$ by performing tests under a normal load of $2 \mathrm{~N}$, frequency of $2 \mathrm{~Hz}$ and stroke length of $3.2 \mathrm{~mm}$ during $30 \mathrm{~min}$ in $52.6 \mathrm{~g} / \mathrm{L} \mathrm{NaCl} \mathrm{so-}$ lution. The authors reported better wear resistance, together with lower change on open circuit potential (OCP) and lower galvanic current under sliding for the nitrided alloy, particularly for the ones treated at $900{ }^{\circ} \mathrm{C}$.

Furthermore, in the literature, most of TiN coatings have been performed at high deposition temperatures $\left(500-1100{ }^{\circ} \mathrm{C}\right)$ $[6,22,28,31,33-38]$, which may cause mechanical, microstructural and chemical damage to the substrate [39-41]. Therefore, sputtering is a promising route due to easy control of deposition rate, high ionization rate, creation of high-density plasma, and preferable energy of deposition material improving the adhesion of coating layer [42]. The present study was aimed at studying the corrosion and tribocorrosion behaviour of TiN thin films produced by RF sputtering on Ti grade 4 in a $9 \mathrm{~g} / \mathrm{L} \mathrm{NaCl}$ solution at body temperature, as well as to have a preliminary understanding to the influence of the deposition time on the tribocorrosion mechanisms by characterizing worn surfaces and subsurfaces.

\section{Experimental procedure}

\subsection{Materials and processing}

ASTM F67 grade 4 pure titanium (ACNIS) was used as substrate material and grinded with $\mathrm{SiC}$ paper down to 800 mesh size $\left(\mathrm{R}_{\mathrm{a}}=0.20 \pm 0.01 \mu \mathrm{m}\right)$ by an automatic polishing machine. After grinding, samples were cleaned in an ultrasonic bath in deionized water, acetone and propanol for $10 \mathrm{~min}$, respectively. TiN hard ceramic coatings were deposited on the substrate by RF sputtering technique (13.6 MHz power supply). Before TiN deposition, the residual pressure was below $10^{-6}$ Torr and substrate surface was sputtered in pure argon plasma in order to minimize the surface impurities. A resistance heater was used to keep the temperature at $400{ }^{\circ} \mathrm{C}$ and all samples were sputtered under $240 \mathrm{~W}$ RF power. The TiN layer was deposited with 40 sccm (standard cubic centimetres per minute) $\mathrm{Ar}$ and $4 \mathrm{sccm} \mathrm{N}_{2}$ flow at constant total pressure of $5 \times 10^{-3}$ Torr for 30 and $80 \mathrm{~min}$ deposition time and labeled as TiN-30 $\mathrm{min}$ and TiN-80 min, respectively.

\subsection{Corrosion and tribocorrosion tests}

Prior to the corrosion and tribocorrosion tests the samples were cleaned ultrasonically in propanol and distilled water for 10 and $5 \mathrm{~min}$, respectively. Uncoated samples were metallographically prepared down to 1200 mesh SiC papers and kept in desiccator for $24 \mathrm{~h}$ before being tested. Corrosion behaviour was evaluated by means of electrochemical impedance spectroscopy (EIS) and potentiodynamic polarization in $9 \mathrm{~g} / \mathrm{L}$ sodium chloride $(\mathrm{NaCl})$ solution at body temperature $\left(37 \pm 2{ }^{\circ} \mathrm{C}\right)$ using Gamry Potentiostat/Galvanostat/ZRA (Reference $600+)$. All corrosion tests were performed in a conventional threeelectrode electrochemical cell where samples were kept as a working electrode with an exposed area of $0.2 \mathrm{~cm}^{2}$, a Pt and saturated calomel electrode (SCE) were used as counter and reference electrode, respectively. Before EIS measurements, the surfaces were stabilized at OCP till $\Delta \mathrm{E}$ was below $60 \mathrm{mV} \mathrm{h}^{-1}$, EIS data were employed at OCP by scanning a range of frequencies from $10^{-2}$ to $10^{5} \mathrm{~Hz}$ with 7 points per frequency decade where the amplitude of the sinusoidal was set as $10 \mathrm{mV}$. After the EIS measurements, potentiodynamic polarization measurements were carried out after $10 \mathrm{~min}$ of delay at OCP, with $0.5 \mathrm{mV} / \mathrm{s}$ scan rate, starting at $-0.25 \mathrm{~V}$ vs. OCP and moving in the anodic direction up to $1.0 \mathrm{~V}_{\mathrm{SCE}}$.

Tribocorrosion tests were performed using a pin-on-plate reciprocating sliding configuration. The testing samples were used as the working electrode with $0.8 \mathrm{~cm}^{2}$ exposed area against a hard and inert counter-body, a $10 \mathrm{~mm}$ diameter alumina ball (Ceratec), and a SCE was used as the counter electrode, connected to a Gamry Potentiostat/ Galvanostat/ZRA (Reference 600). The sliding tests were performed at a normal load of $1 \mathrm{~N}$, a reciprocating sliding frequency of $1 \mathrm{~Hz}$, and linear displacement amplitude of $3 \mathrm{~mm}$ using a tribometer (CETR-UMT2) coupled to the UMT test viewer software to monitor the coefficient of friction (COF). Tribocorrosion tests carried out under OCP, in $30 \mathrm{~mL}$ of $9 \mathrm{~g} / \mathrm{L} \mathrm{NaCl}$ solution at body temperature $\left(37 \pm 2{ }^{\circ} \mathrm{C}\right)$, and consisted of three steps: (i) stabilization at OCP $\left(\Delta \mathrm{E}<60 \mathrm{mVh}^{-1}\right)$ (ii) sliding for $30 \mathrm{~min}$; (ii) removing the load and recording the recovering of OCP during $30 \mathrm{~min}$. All tests were repeated at least three times in order to assure the reproducibility and the results were presented as the arithmetic mean \pm standard deviation.

\subsection{Characterization}

The crystalline structure of the coatings were analysed using grazing incidence X-ray diffraction (XRD, Bruker D8 Discover diffractometer equipped with a $\mathrm{Cu}-\mathrm{K \alpha}$ radiation $(\lambda=0.1544 \mathrm{~nm})$ at $40 \mathrm{kV}$ and $20 \mathrm{~mA})$

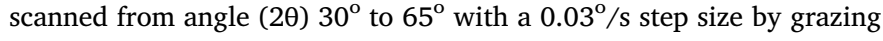
incidence mode at $3^{\circ}$. The phase percentage was calculated through relative intensity of each peak by following Eq. (1).

$\%$ phase $_{\alpha}=\frac{\sum I_{\alpha \text { peaks }}}{\sum I_{\text {all peaks }}}$

Nanoindentation studies were performed to obtain complementary hardness data as well as information on Young's modulus $(E)$. Data were obtained from 8 indentations on different locations using a depthcontrolled test as maximum depth of $120 \mathrm{~nm}, 0.2 \mathrm{~m} \mathrm{~N} / \mathrm{s}$ loading/unloading rate, and $5 \mathrm{~s}$ dwell time. The average surface roughness $\left(\mathrm{R}_{\mathrm{a}}\right)$ were measured on three different sample by profilometry (Veeco, Dektak 150). The Daimler-Benz Rockwell-C adhesion test has been used in literature [43-46] as a fast and easy method to evaluate the adhesion of various coatings. This test was performed by using a Rockwell ' $\mathrm{C}$ ' indenter with a load of $150 \mathrm{~kg}$ for at least three indentions by using Officine Galileo Mod. D200 tester.

After each tribocorrosion test, samples were ultrasonically cleaned for $10 \mathrm{~min}$ in propanol and $5 \mathrm{~min}$ in distilled water, respectively. The wear tracks and worn counter-body surfaces were characterized by SEM using FEI Nova 200 field emission gun scanning electron microscope (FEG-SEM) equipped with energy dispersive X-Ray spectroscopy (EDS). All worn surface images were taken parallel to the sliding direction by using backscattered (BSE) and secondary electron (SE) detector whereas sub-worn surface images were taken perpendicular to the sliding direction. The 2D wear track profiles were obtained by a surface profiler (Veeco, Dektak 150), and total wear volume loss was determined following the model and calculation procedure given elsewhere [47].

The cross-sections of the TiN coatings and subsurface of wear tracks were prepared and characterized by using FEI Helios NanoLab 450S DualBeam - FIB (focused ion beam) with UHREM FEG-SEM. To protect the films, first a few hundred $\mathrm{nm}$ of Pt protection was deposited on $15 \times 2 \mu \mathrm{m}^{2}$ area with the electron beam using $6.4 \mathrm{nA}$ current accelerated at $3 \mathrm{kV}$. Afterwards, $1-3 \mu \mathrm{m}$ of Pt protective strap was deposited with $80 \mathrm{pA} \mathrm{Ga}^{+}$ion at $30 \mathrm{kV}$. Bulk milling was performed with $9.3 \mathrm{nA}$, and fine milling (polishing) was performed on the edge of the trenches with $2.5 \mathrm{nA}$, both at $30 \mathrm{kV}$. Finally, cross-sectional images were taken with SE mode at the accelerating voltage of $10 \mathrm{kV}$.

\section{Results}

\subsection{Surface characterization}

The XRD spectra obtained on the TiN-30 min and TiN-80 min samples are presented in Fig. 1. TiN-30 min samples exhibited high- 


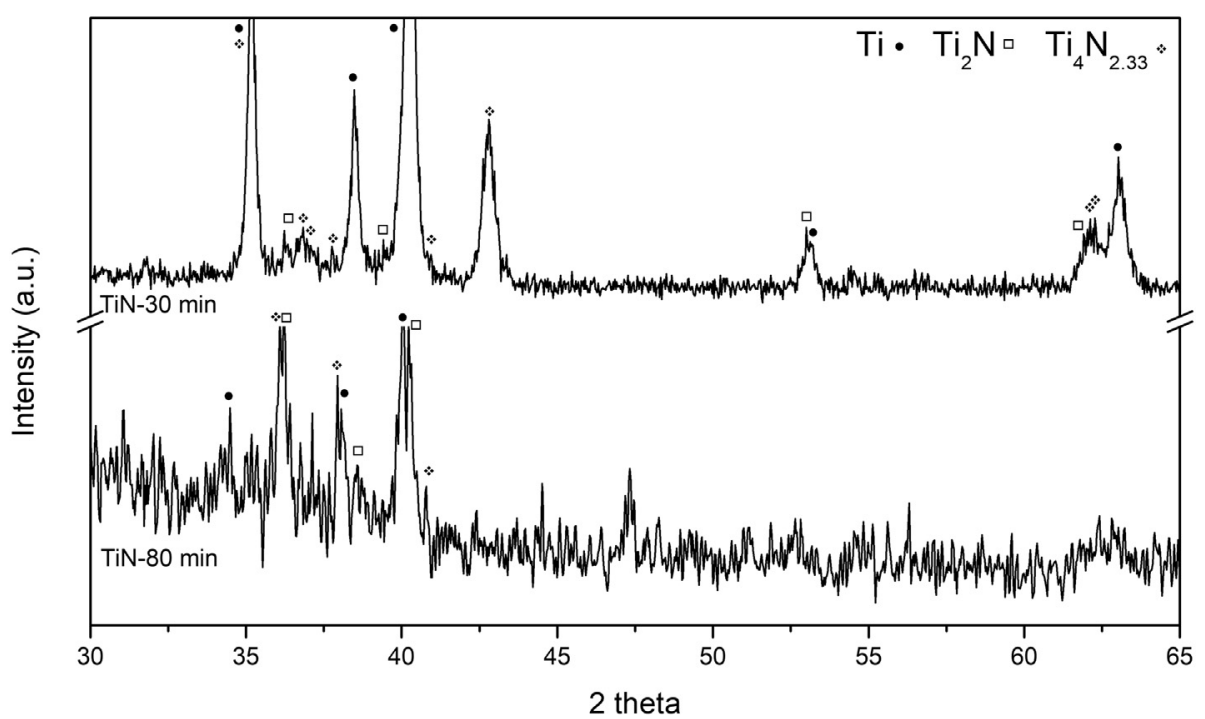

Fig. 1. XRD patterns of TiN coated samples.

intensity peaks characteristics of the hexagonal $\alpha$-Ti phase (ICDD 00-044-1294) from the substrate. Regarding the thin film, the tetragonal $\mathrm{Ti}_{2} \mathrm{~N}$ phase (ICDD 00-017-0386), and rhombohedral $\mathrm{Ti}_{4} \mathrm{~N}_{2.33}$ phase (ICDD 01-089-5210) could be identified. The identified diffraction peaks were well matched to corresponding cards, however, a slight shift occurred on $\mathrm{Ti}_{4} \mathrm{~N}_{2.33}$ and $\mathrm{Ti}_{2} \mathrm{~N}$ peaks for TiN-80 min which may be due to the residual stresses in the coating [38]. By increasing the deposition time to $80 \mathrm{~min}$, the XRD pattern revealed the same phases, however, the relative intensities of $\mathrm{Ti}_{4} \mathrm{~N}_{2.33}$ and $\mathrm{Ti}_{2} \mathrm{~N}$ phases were higher, indicating that a thicker film was present, as expected from the longer deposition time. Relative intensity of $\mathrm{Ti}_{2} \mathrm{~N}$ phase was observed to be increased on TiN-80 min samples. Also, the phase percentages (phase distribution) regarding TiN coatings were calculated by Eq. (1), and the results showed that the coating film on TiN-30 min was a combination of $75 \% \mathrm{Ti}_{4} \mathrm{~N}_{2.33}$ and $25 \% \mathrm{Ti}_{2} \mathrm{~N}$, while the coating film on TiN-80 min was a combination of $46 \% \mathrm{Ti}_{4} \mathrm{~N}_{2.33}$ and $54 \% \mathrm{Ti}_{2} \mathrm{~N}$. Thus, in addition to obtaining a relatively thicker and rougher surface, increased deposition time also seems to promote the formation of $\mathrm{Ti}_{2} \mathrm{~N}$ phase on the coating layer, which may contribute to obtain harder and more mechanicallyresistant surfaces on TiN-80 min samples [48].

Fig. 2 presents the cross-sectional FIB-SEM micrographs of TiN coated samples showing the continuous coating layer. Thickness of the films were estimated to be of $148 \pm 13 \mathrm{~nm}$ and $209 \pm 6 \mathrm{~nm}$ for TiN$30 \mathrm{~min}$ and TiN-80 min, respectively.

The hardness and Young's modulus of uncoated Ti and TiN coated samples calculated from the nanoindentation tests are given in Table 1 together with the average roughness $\left(R_{a}\right)$ values. As can be seen in Table 1, the hardness values were significantly higher on the coated samples as compared to the values calculated for the bare metal. Besides, average values of Young's modulus were close to those observed in the substrate for the TiN-30 min samples. However, a noticeable increase was observed for the TiN-80 min samples. On the other hand, it was also observed that both hardness and Young's modulus increased on the coated samples with increasing the deposition time. The $R_{a}$ value of TiN coated samples was higher than uncoated sample, while the $R_{a}$ values was significantly increased with increasing deposition time that is known to be influenced by the atomic shadowing effect [49], structural orientation of the coating [50], and change of coating density [49].

Fig. 3 shows Rockwell ' $\mathrm{C}$ ' indentations on the coating samples. There was no evidence of coating delamination for both samples although micro cracks were observed on TiN-30 min samples (insert on Fig. 3a) and relatively larger radial cracks were observed on TiN-80 min samples. According to the Daimler-Benz Rockwell-C method, the layer damage adjacent to the boundary of the Rockwell indentation can be evaluated by microscopy and classifying the adhesion as HF1 to HF6 according to the level of cracking and coating delamination around the indentation. The indentations classified as HF1 and HF2 correspond to sufficient adhesion where only cracks are observed, whereas both cracks and deleminations are observed for HF3 to HF5, and finally, only deleminations are observed for HF6 [51]. Thus, it can be stated that TiN-30 min and TiN-80 min samples presented acceptable interfacial adhesion corresponding to HF1 and HF2, respectively.

\subsection{Corrosion behaviour}

Fig. 4 shows representative potentiodynamic polarization curves of the uncoated and TiN coated samples obtained in $9 \mathrm{~g} / \mathrm{L} \mathrm{NaCl}$ solution at body temperature. The uncoated samples exhibited a well-defined passivation plateau above around $150 \mathrm{mV}$, whereas the TiN coated samples did not present an evident passivation plateau, even though they exhibited lower current densities on the anodic domain in the potential range tested. Moreover, the current densities recorded for the TiN coating deposited for 80 min were always lower than the ones recorded for the coatings with shorter deposition time, indicating higher corrosion resistance for $\mathrm{TiN}-80 \mathrm{~min}$ samples. The corrosion potentials $\left(\mathrm{E}_{(i=0)}\right)$ and the passivation current densities $\left(i_{\text {pass }}\right)$ derived from the polarization curves are given in Table 2 , and $i_{\text {pass }}$ values for all samples were taken at $0.5 \mathrm{~V}$ vs. SCE.

As can be seen in Table 2, $\mathrm{E}_{(i=0)}$ values of TiN coated samples were significantly higher than that of the uncoated samples, confirming a lower tendency to corrosion for coated samples. On the other hand, $i_{\text {pass }}$ of both TiN coated samples were significantly lower as compared to the uncoated samples, while, the $i_{\text {pass }}$ value of the TiN- 80 min was observed lower than the TiN-30 min sample.

Representative electrochemical impedance spectra of the uncoated and TiN coated samples are presented in Fig. 5 (Nyquist and Bode diagrams). It can be observed from the Nyquist diagram (Fig. 5a) that TiN coated samples presented a larger diameter of semi-circle indicating a higher corrosion resistance when compared to the uncoated samples. The improved corrosion resistance was also reflected by a slight increase on total impedance values $(|\mathrm{Z}|)$ represented in the Bode diagram (Fig. 5b). Comparing the TiN coated samples, it was possible to observe that the semi-circle diameter was slightly larger for TiN-80 min as compared to TiN-30 min. The constant values of $|\mathrm{Z}|$ observed in Bode diagram (Fig. 5b) at high frequencies for all samples, where the phase 


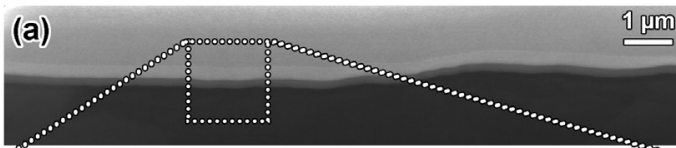

(c)

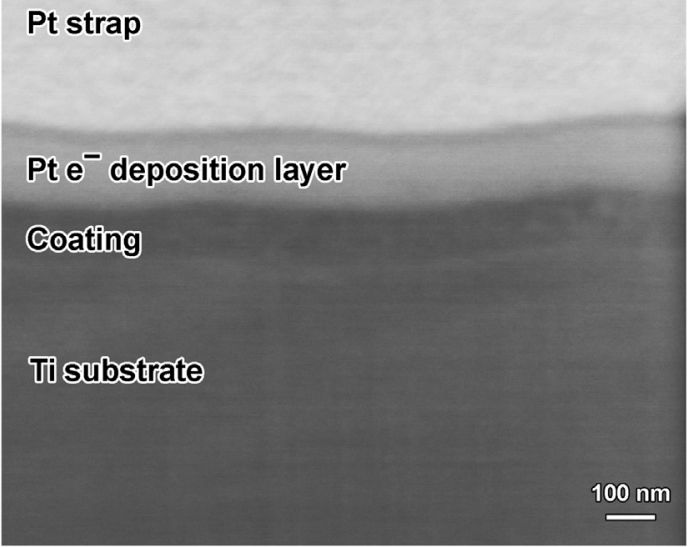

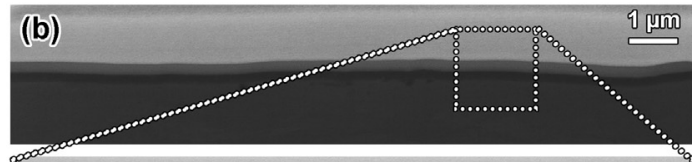

(d)

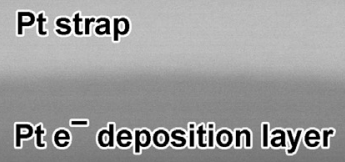

Coating

Tit substrate

Fig. 2. Lower (a, b) and higher (c,d) magnification SEM cross-section images of TiN-30 min and TiN-80 min samples, respectively.

Table 1

Hardness, Young's modulus, and $\mathrm{R}_{\mathrm{a}}$ values.

\begin{tabular}{lccc}
\hline Sample & $\begin{array}{c}\text { Hardness } \\
(\mathrm{GPa})\end{array}$ & $\begin{array}{c}\text { Young's Modulus } \\
(\mathrm{GPa})\end{array}$ & $\begin{array}{c}\text { Average surface } \\
\text { roughness-Ra }(\mu \mathrm{m})\end{array}$ \\
\hline $\mathrm{Ti}$ & $2.9 \pm 0.7$ & $104.4 \pm 18$ & $0.19 \pm 0.02$ \\
$\mathrm{TiN}-30 \mathrm{~min}$ & $5.0 \pm 1.0$ & $109.6 \pm 17.5$ & $0.22 \pm 0.01$ \\
TiN-80 min & $7.1 \pm 0.6$ & $149.5 \pm 9.8$ & $0.58 \pm 0.05$ \\
\hline
\end{tabular}

angle was near $0^{\circ}$, as the typical response of electrolyte resistance. In low and middle frequency ranges, the phase angle values approached values close to $-90^{\circ}$ for both substrate and coated samples. In the case of the substrate, this behaviour indicates a typical capacitive response of the native oxide film formed on the substrate surface. Regarding the coated samples, the phase angle values were kept almost constant (approaching $-90^{\circ}$ ) till the lowest frequencies, indicating the protector character of the TiN coatings.

The electrical equivalent circuits (EECs) presented in Fig. 6 were used to fit experimental EIS data by using Gamry Echem Analyst software (version 5.61). The EIS experimental data of the uncoated samples was fitted by using a modified Randle's circuit (Fig. 6a) containing elements representing the electrolyte resistance $\left(R_{e}\right)$, the native oxide film resistance $\left(\mathrm{R}_{\text {nox }}\right)$ and constant phase element (CPE) considering a non-ideal capacitance of the native oxide film $\left(\mathrm{Q}_{\text {nox }}\right)$. In fact, the impedance of the CPE is defined as:

$Z_{C P E}=\left[Y_{0}(j w)^{n}\right]^{-1}$

where $Y_{O}$ is a frequency-independent constant, $j=\sqrt{(-1)}, w$ is the angular frequency, and $\mathrm{n}$ is the fractional exponent which is in the $-1 \leq n \leq 1$ range. When $n=1$, the CPE response is that of a pure

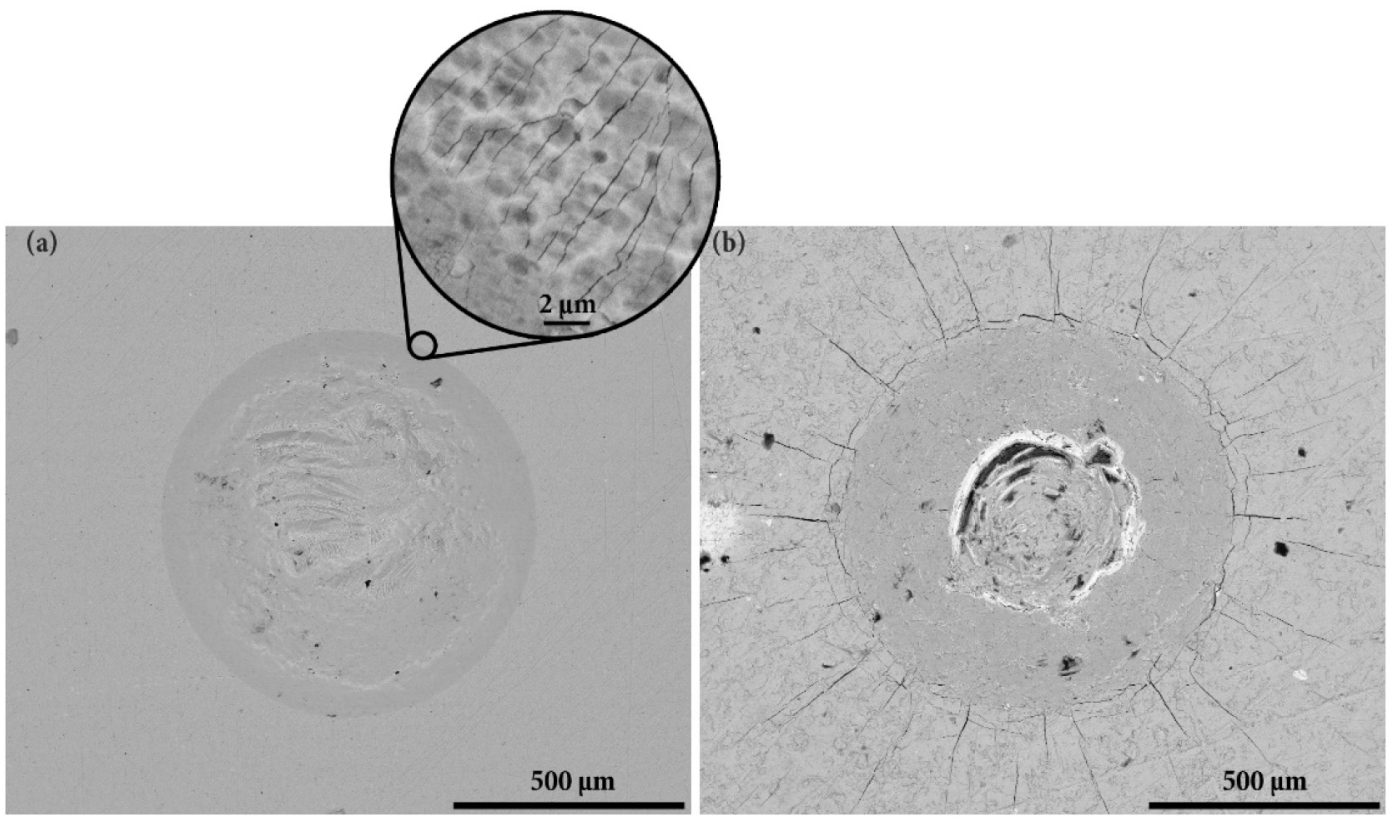

Fig. 3. BSE SEM images of Daimler-Benz adhesion test on (a) TiN-30 min and (b) TiN-80 min samples. 


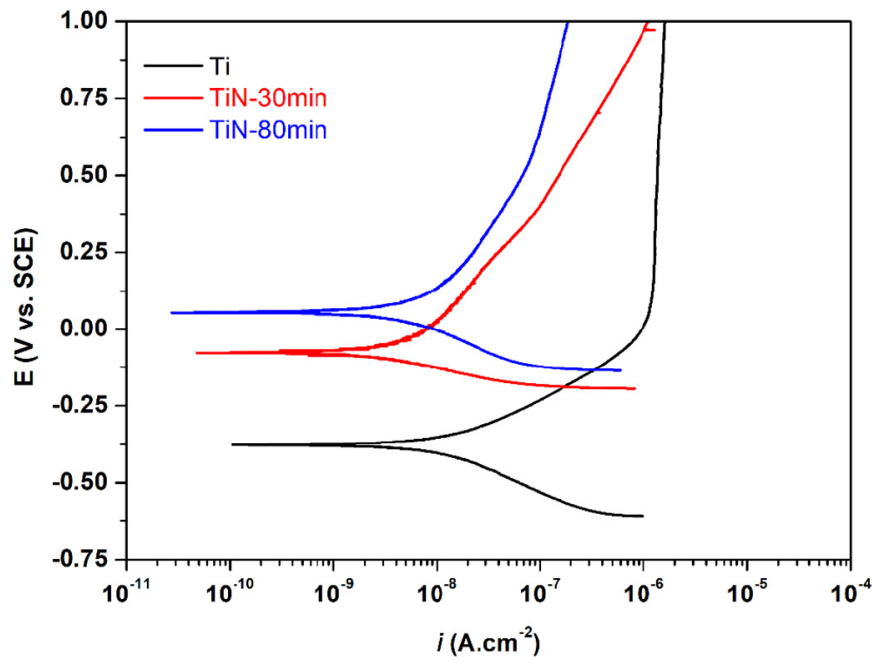

Fig. 4. Potentiodynamic polarization curves.

Table 2

Electrochemical parameters derived from the potentiodynamic polarization curves.

\begin{tabular}{lcc}
\hline & $E_{(i=0)}\left(V_{S C E}\right)$ & $i_{\text {pass }}\left(\mu \mathrm{Acm}^{-2}\right)$ \\
\hline Ti & $-0.371 \pm 0.018$ & $1.37 \pm 0.04$ \\
TiN-30 min & $-0.065 \pm 0.022$ & $0.11 \pm 0.03$ \\
TiN-80 min & $0.009 \pm 0.046$ & $0.07 \pm 0.02$ \\
\hline
\end{tabular}

capacitor, while $n=0$ and $n=-1$ corresponds to a resistor and inductor response, respectively. The $n$ value is influenced by surface heterogeneities and its roughness, thus this element may be described as a non-ideal capacitor, when $\mathrm{n}$ value is close to 1 [52].

Fig. $6 \mathrm{~b}$ represents the EEC used for TiN coated samples. Elements of this circuit includes electrolyte resistance $\left(R_{e}\right)$, while a pair $R_{\text {coat }} / Q_{\text {coat }}$ should be added to represent the contribution of the resistance and capacitance of the TiN coating. However, since the $\mathrm{R}_{\text {coat }}$ tends to be extremely high due to the strong insulating properties of the TiN film, this element was removed from the EEC. Furthermore, in order to represent the corrosion process that takes place inside the defects of the TiN coating, a pair of $R_{b l} / Q_{b l}$ was added in series with the additional electrolyte resistance inside those defects. The barrier layer resistance $\left(R_{b 1}\right)$ represents the preferential sites for corrosion in the defects and the $\mathrm{Q}_{\mathrm{bl}}$ regards the defect layer effect.

The quality of the equivalent circuits used for fitting was evaluated

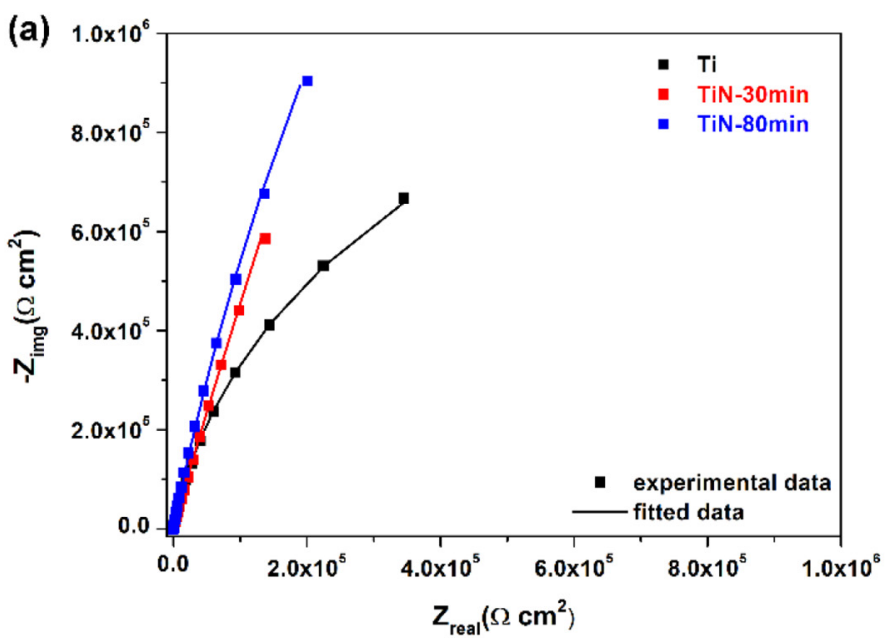

by the goodness of fitting $\left(\chi^{2}\right)$. All samples presented a good fitting to the corresponded EECs exhibiting $\chi^{2}$ values below $10^{-3}$. $Q_{\text {coat }}, Q_{\text {nox }}$ and $\mathrm{Q}_{\mathrm{bl}}$ values were converted to $\mathrm{C}_{\text {coat }}$ (capacitance of TiN coating) and $\mathrm{C}_{\mathrm{bl}}$ (capacitance of the barrier layer) by using Eqs. (3) and (4), respectively, derived from Brug's equation [53].

$C_{\text {nox } / \text { coat }}=\left[Q_{\text {nox } / \text { coat }} R_{e}^{(1-n)}\right]^{\frac{1}{n}}$

$C_{b l}=\left[Q_{b l}\left(R_{e}+R_{e^{\prime}}\right)^{(1-n)}\right]^{\frac{1}{n}}$

\subsection{Tribocorrosion behaviour}

The evolution of OCP before, during and after sliding in $9 \mathrm{~g} / \mathrm{L} \mathrm{NaCl}$ solution is shown in Fig. 7 together with the COF values recorded during sliding. Before sliding, all samples presented stable OCP values due to the presence of a passive film on the uncoated samples and a stable nitride layer on the coated samples.

In case of uncoated $\mathrm{Ti}$, when sliding started, a sudden decrease in OCP was detected, that confirmed the removal of passive film due to mechanical damage and pointing an increased tendency to corrosion in the wear track region [54]. For the TiN-30 min samples, after sliding started, the OCP values gradually decreased till approximately -0.35 $\mathrm{V}_{\mathrm{SCE}}$ then suddenly dropped to lower values, around $-0.7 \mathrm{~V}_{\mathrm{SCE}}$, similar to those observed on the uncoated samples at the beginning of sliding. After this, local increments were recorded during sliding. The first gradual drop in the OCP observed at the beginning of sliding can be linked to a local damage of TiN coating, and the second sharp drop shows the destruction of the TiN coating on the contact region with the alumina ball resulting on the exposure of the bare Ti substrate to the solution (indicated by arrows on Fig. 7). Regarding TiN-80 min samples, a very small drop on the OCP values (around $40 \mathrm{mV}$ ) was suddenly recorded at the beginning of sliding. Then the OCP values gradually decreased till approximately $-0.30 \mathrm{~V}_{\mathrm{SCE}}$ and remained relatively constant at this value till the end of sliding. After sliding, the OCP values of all samples increased near to the values recorded before sliding due to recovering of the passive oxide film on the damaged Ti area [22].

Evolution of COF can be also seen on Fig. 7. Once sliding started, COF value of the uncoated samples reached values around 0.4 , in a short period. As sliding continued, COF of the uncoated samples kept relatively constant till around $650 \mathrm{~s}$ and after that an increment was recorded with a correspondence with a slight increase on OCP values. Regarding the TiN-30 min samples, the initial decrease of OCP corresponded to an increase on COF values till around 0.7, after this, a sharp drop to around 0.45 was observed that can be due to removal and/or wear out of the TiN coating. Afterwards, local increments were observed during sliding, similar to the behaviour observed on the

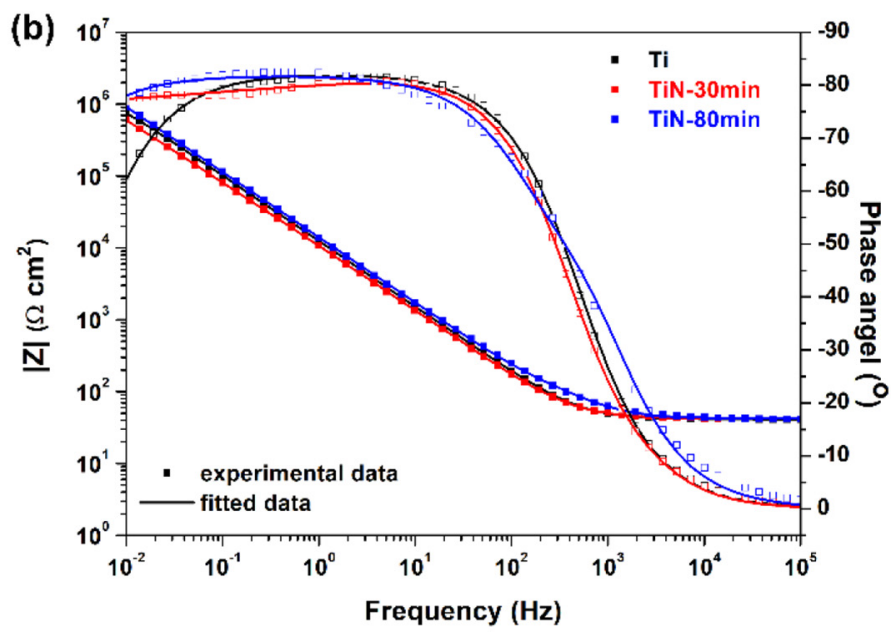

Fig. 5. (a) Nyquist and (b) Bode diagrams of EIS spectra. 

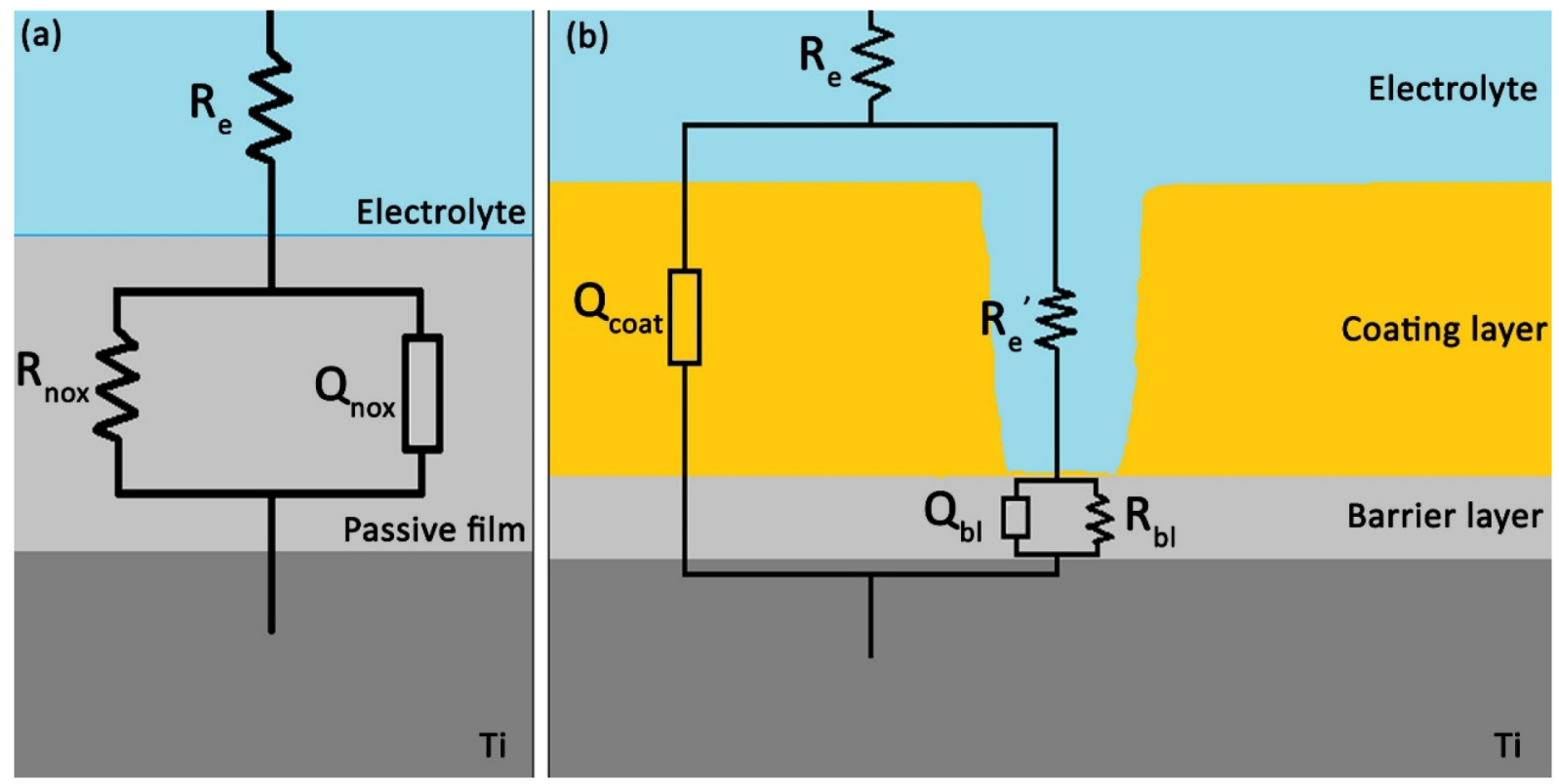

Fig. 6. EECs used for fitting EIS experimental data for a) the uncoated and b) TiN coated samples.
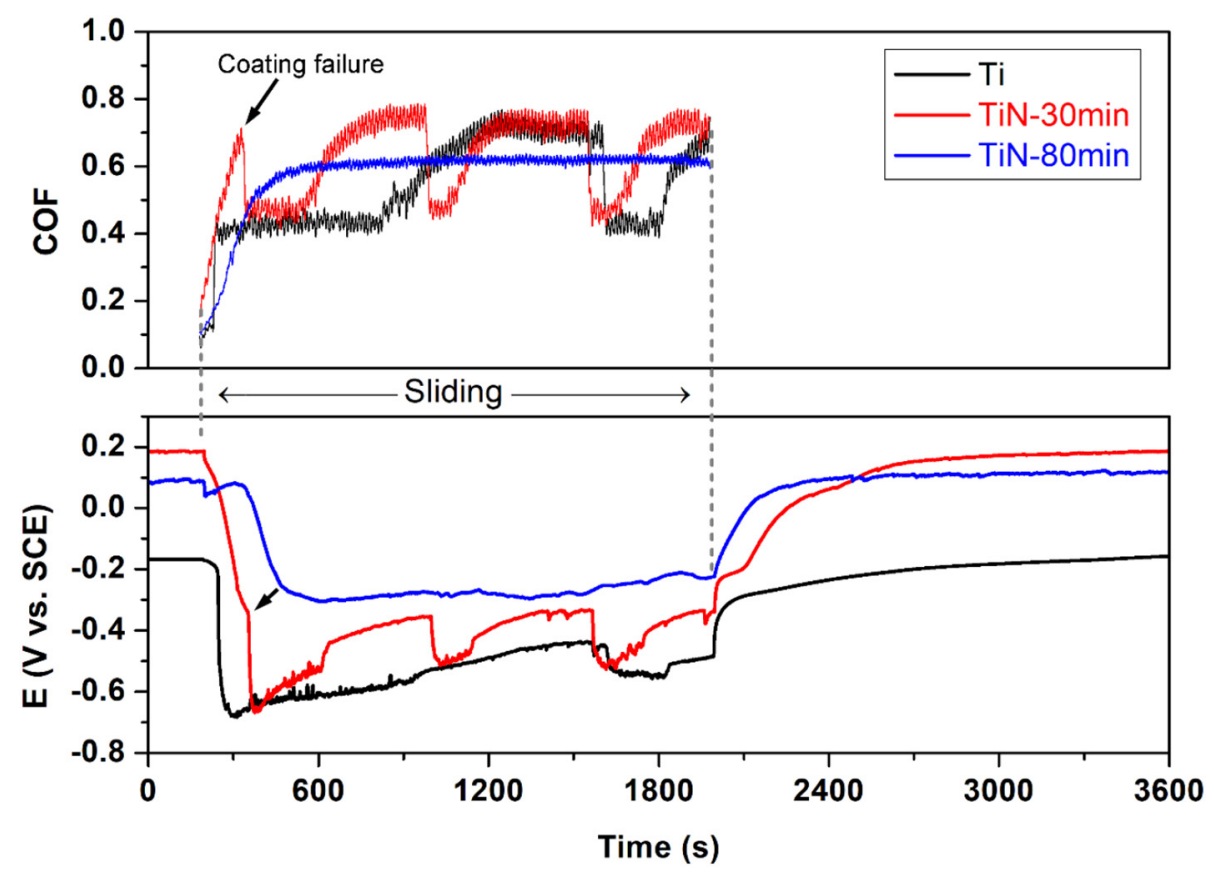

Fig. 7. The representative evolution of OCP before, during, and after sliding, together with evolution of COF under sliding for the uncoated and TiN coated samples in $9 \mathrm{~g} / \mathrm{L} \mathrm{NaCl}$.

uncoated samples. Regarding the TiN-80 min samples, COF values increased up to approximately 0.6 and then stayed relatively stable with minor oscillations till the end of sliding.

Representative lower magnification SEM images of wear tracks are shown in Fig. 8a-c. TiN-80 min samples presented significantly lower wear damage compared to the other samples. Worn surface features can be seen in more detail on the representative higher magnification SEM images given in Fig. 8d-f. The uncoated $\mathrm{Ti}$ and TiN-30 min sample surfaces exhibited typical worn surface features for Ti, namely parallel sliding grooves, adhered/oxidized patches (verified by the presence of oxygen on the EDS spectra presented in Fig. $8 \mathrm{~g}$ and h), and plastic deformation. However, the worn surfaces of TiN-80 min samples were dissimilar to other two samples. It can be seen that the damage of the surface of the TiN-80 min samples was much less severe, and denser oxidized patches (black areas on Fig. 8f and corresponding EDS spectrum on Fig. 8i) were observed.

Hertzian contact pressures were calculated by using the measured Young's modulus values for TiN-30 min and TiN-80 min. The Young's modulus and Poisson ratio of cp Ti grade 4 [55] and alumina ball [56], as well, the Poisson ratio of TiN [57] were taken from the literature. The chosen normal load $(1 \mathrm{~N})$ corresponds to a maximum Hertzian contact pressure of approx. $390 \mathrm{MPa}$ for Ti and TiN-30 min, and approx. $460 \mathrm{MPa}$ for TiN-80 min, being lower than the reported yield strength of cp Ti grade 4, that is $480 \mathrm{MPa}$ [55].

In order to have a further understanding on the wear mechanism, FIB prepared cross-sectional SEM images of the worn sub-surfaces, taken as perpendicular to the sliding direction, were observed (Fig. 9). As it can be seen in Fig. 9a and d, relatively thick adhered/oxidized 

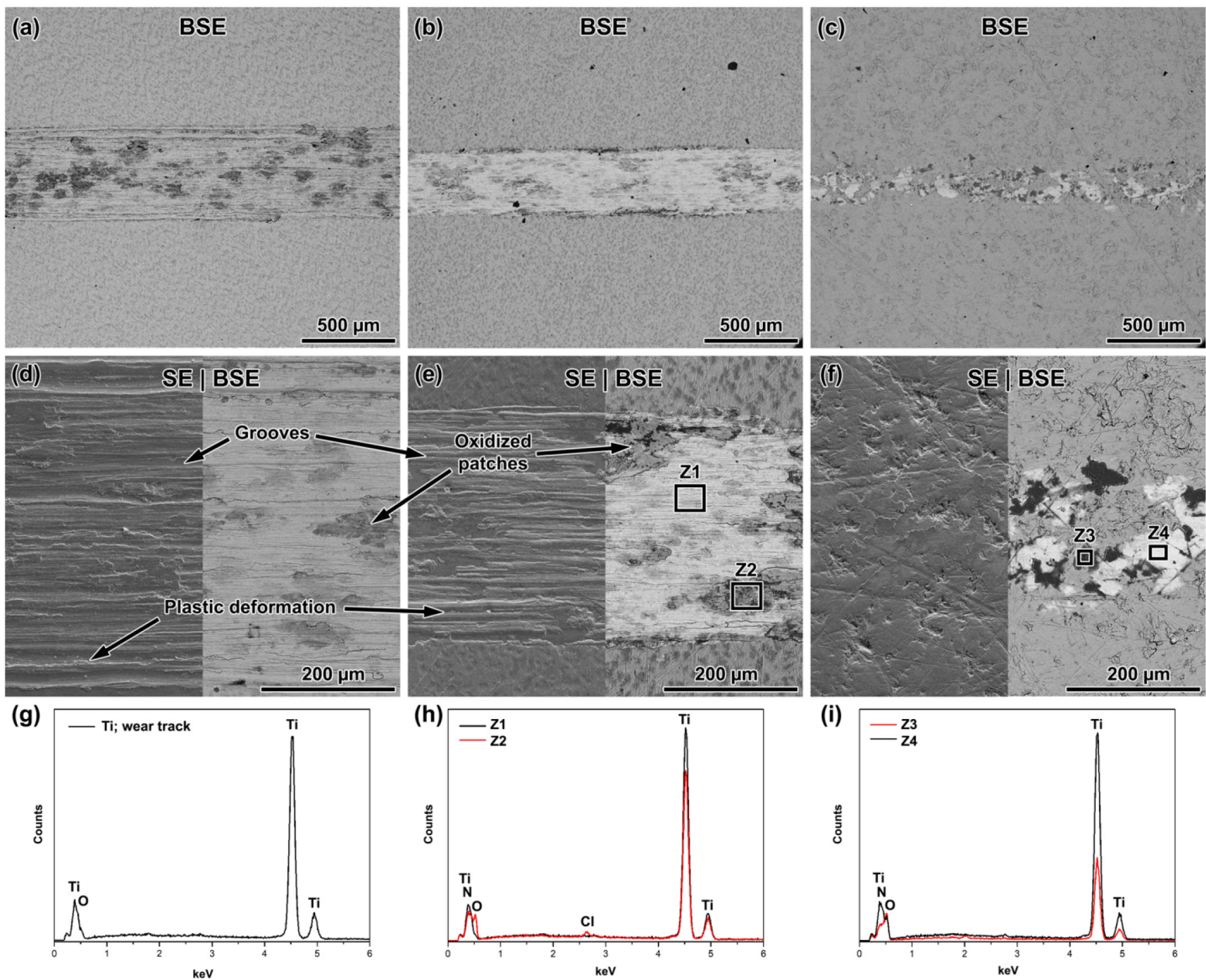

Fig. 8. Lower (a, b, c) and higher (d, e, f) magnification SEM images of the worn surfaces of Ti, TiN-30 min, and TiN-80 min, respectively, together with the EDS spectrum of the Ti worn surface ( $\mathrm{g}$ ) and EDS spectra taken from the marked zones of the coated samples (h, i).

patches were found on the uncoated Ti samples. As oppose to the other samples, some cracks were observed on the worn areas of the TiN80 min samples. The coating layer was not observed under most of the patches, grooves (TiN-30 min) or damaged areas (TiN-80 min, represented by Z4 on Fig. 9f), due to the damage given by abrasive and adhesive wear actions.

The SEM images and respective EDS spectra taken from the wear scars on the alumina balls used as counter-material are presented in Fig. 10. The wear scars on the balls that slid against the uncoated samples were much larger than that observed on the balls used to test the coated samples, which is in accordance with the dimensions of the wear tracks shown in Fig. 8. Transference of Ti to the alumina counterbody was detected in all surfaces by EDS analysis, indicating adhesive wear. However, that phenomenon was much pronounced in the uncoated samples.

The representative 2D wear track profiles taken from centre of the wear tracks are presented in Fig. 11. The uncoated Ti and TiN-30 min samples presented similar wear track profiles, whereas much lower volume loss was observed on the TiN- 80 min samples. The wear volume loss values were calculated as $(2.8 \pm 0.5) \times 10^{-3} \mathrm{~mm}^{3}$, $(3.3 \pm 1.0) \times 10^{-3} \mathrm{~mm}^{3}$, and $(0.4 \pm 0.2) \times 10^{-3} \mathrm{~mm}^{3}$ for the uncoated Ti, TiN-30 min, and TiN-80 min, respectively.

\section{Discussion}

\subsection{Corrosion behaviour}

TiN coatings are commonly used to increase the corrosion resistance of metallic biomaterials [58]. Corrosion tests showed that the TiN coated samples presented lower tendency to corrosion and lower corrosion rate due to nobler potential and lower passive current density (Figs. 3 and 4) as also previously been reported for TiN coated on $\mathrm{Ti}$ [59], Ti-6Al-4 V [60], Ti-6Al-7Nb [61], Ti-35Nb-7Zr-5Ta [25], and Ti$25 \mathrm{Ta}-25 \mathrm{Nb}$ alloy [62]. On the other hand, TiN-80 min samples presented higher corrosion resistance as compared to TiN-30 min. That may be related to the differences on the TiN coating thickness, that was not linearly proportional to the deposition time possibly due to the substoichiometric phase transformation resulted in changing of crystalline structure and lattice parameters [63], together with the increase on the amount of the $\mathrm{Ti}_{2} \mathrm{~N}$ phase that is known for its more stable behaviour and good electrochemical response [35,60]. Nevertheless, the increase on the passive current densities of the TiN coated samples during the potentiodynamic polarization tests (less pronounced for the TiN-80 min samples) might be attributed to the oxidation of the $\mathrm{Ti}_{2} \mathrm{~N}$ and $\mathrm{Ti}_{4} \mathrm{~N}_{2.33}$ phases [22,64], by a process similar to that reported by Pohrelyuk et al. 


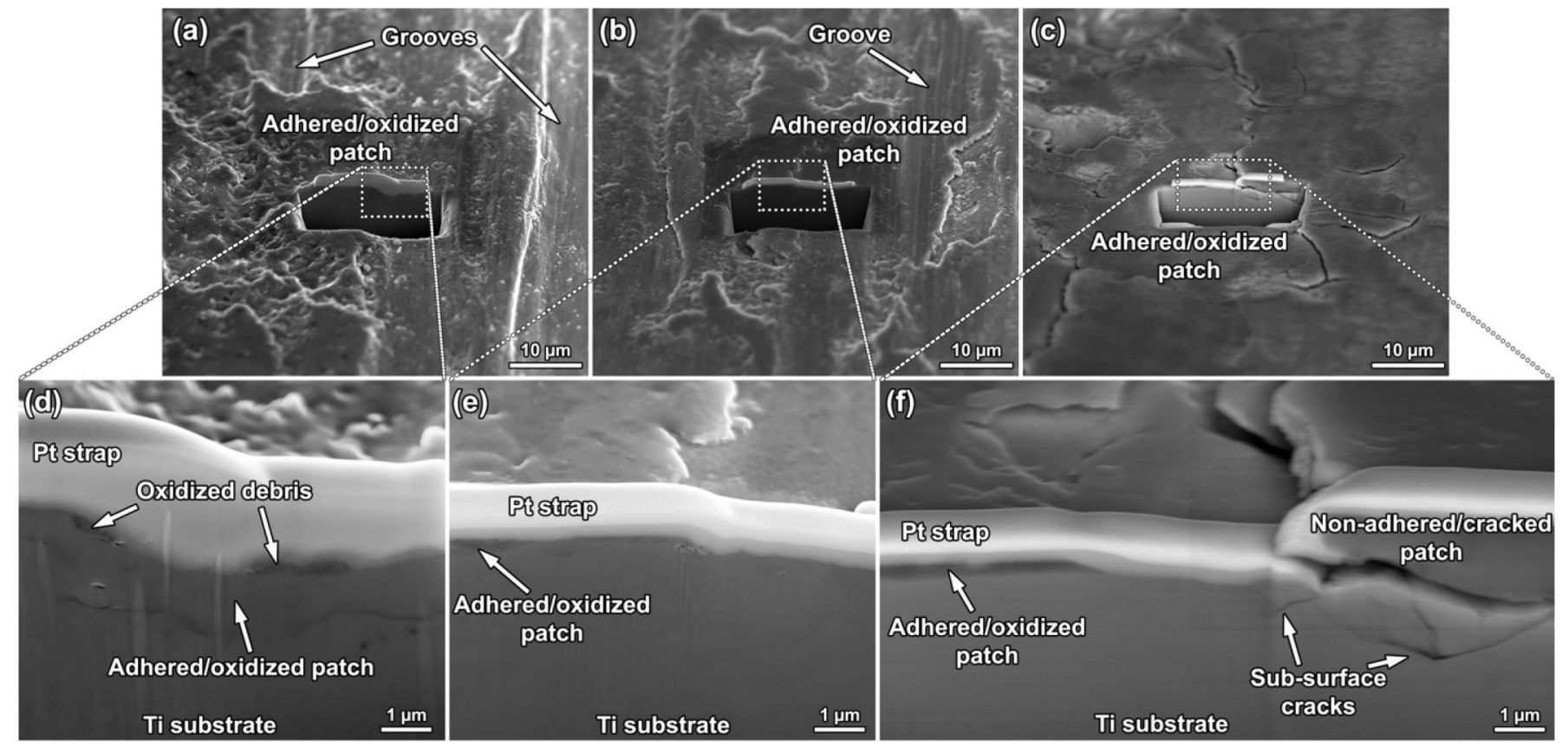

Fig. 9. Lower magnification SE/SEM images (a, b, c) showing FIB milling zones on the wear tracks, and higher (d, e, f) magnification SE/SEM images of the worn subsurfaces of Ti, TiN-30 min, and TiN-80 min, respectively.

[32] for the oxidation of the TiN phase, according to the reaction (1), $2 \mathrm{TiN}+2 \mathrm{yH}_{2} \mathrm{O} \rightarrow 2 \mathrm{TiN}_{\mathrm{x}} \mathrm{O}_{\mathrm{y}}+(1-\mathrm{x}) \mathrm{N}_{2}+4 \mathrm{yH}^{+}+4 \mathrm{ye}^{-}$

The EEC parameters deducted from the fitting of the EIS data for the uncoated and TiN coated samples are presented in Table 3. The values of the resistance and capacitance of native oxide film formed on the uncoated samples were around $2.06 \mathrm{M} \Omega \mathrm{cm}^{2}$ and $7.73 \mu \mathrm{F} \mathrm{cm}^{-2}$, respectively, suggesting a high corrosion resistance of the typical passive films formed on Ti surfaces. Regarding the coated samples, when the deposition time increased from $30 \mathrm{~min}$ to $80 \mathrm{~min}$, a slight decrease on the capacitance values of the TiN coatings $\left(\mathrm{C}_{\text {coat }}\right)$ was observed, indicating an improvement on the corrosion resistance. Furthermore, the capacitance values of TiN coatings were lower when compared with the capacitance of the native oxide film formed on the substrate, indicating better corrosion protection characteristics of these coatings.

\subsection{Tribocorrosion behaviour}

Evolution of OCP and COF during sliding, as well, the analysis of the worn surfaces after tribocorrosion tests revealed that the relative amount of phases presented in the coatings together with the deposition

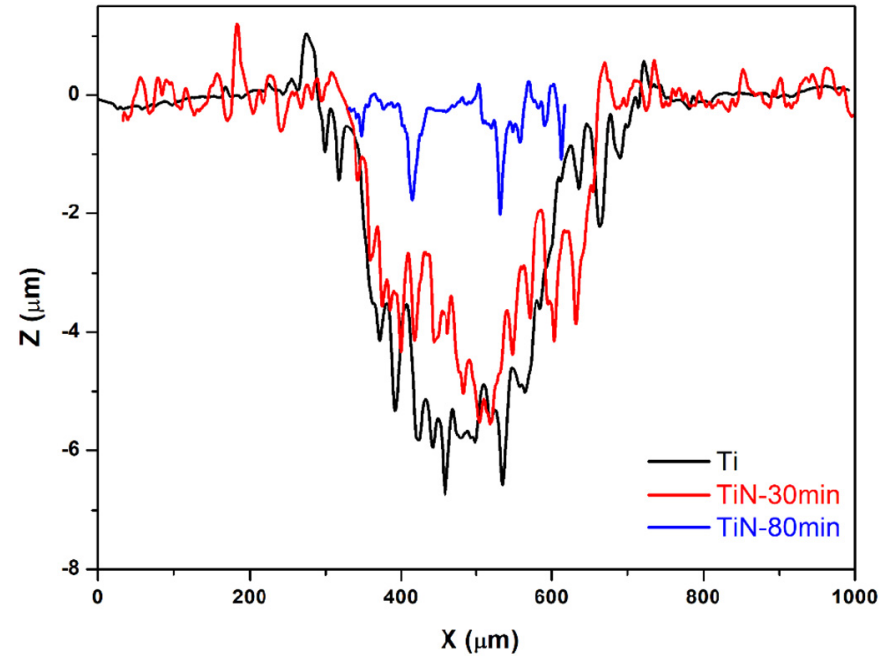

Fig. 11. Representative 2D wear track profiles.
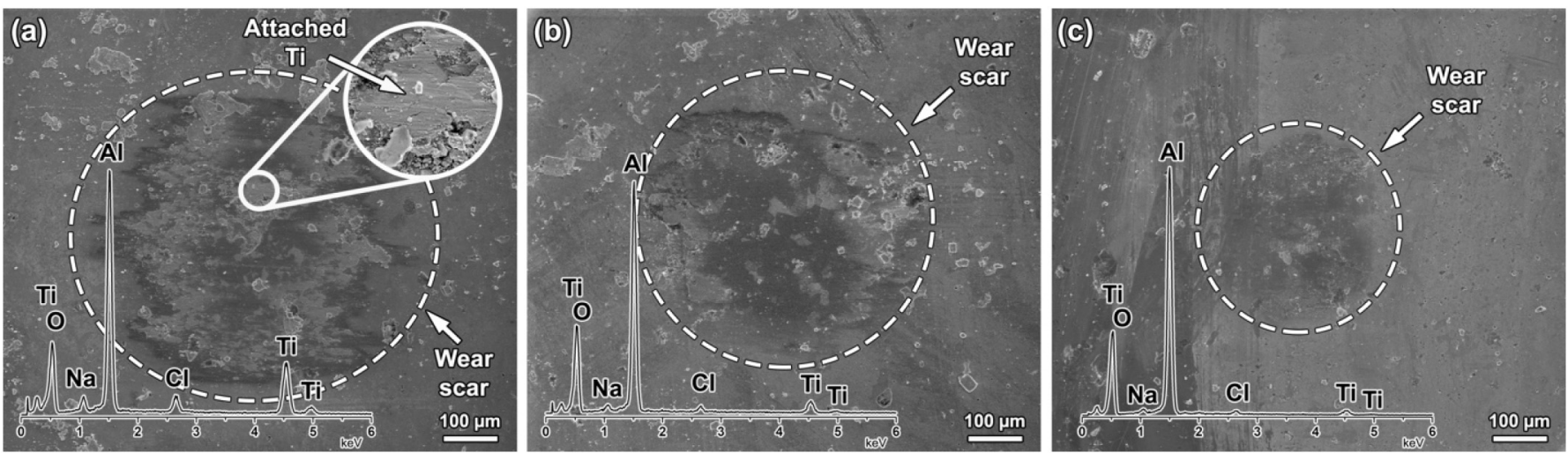

Fig. 10. SE/SEM images of the wear scars on the counter-material surfaces slid against Ti (a), TiN-30 min (b), and TiN-80 min (c), together with EDS spectra taken from each wear scar. 
Table 3

Equivalent circuit parameters obtained from EIS data.

\begin{tabular}{cccc} 
& $\mathrm{Ti}$ & TiN-30 min & TiN-80 min \\
\hline $\mathrm{R}_{\text {nox }}\left(\mathrm{M} \Omega \mathrm{cm}^{2}\right)$ & $2.06 \pm 0.33$ & - & - \\
$\mathrm{C}_{\text {nox }}\left(\mu \mathrm{F} \mathrm{cm}^{-2}\right)$ & $7.73 \pm 0.36$ & - & - \\
$\mathrm{n}_{\text {nox }}$ & $0.92 \pm 0.01$ & - & - \\
$\left.\mathrm{C}_{\text {coat }}(\mu \mathrm{F} \mathrm{cm})^{-2}\right)$ & - & $4.87 \pm 1.43$ & $3.08 \pm 1.07$ \\
$\mathrm{n}_{\text {coat }}$ & - & $0.94 \pm 0.03$ & $0.90 \pm 0.02$ \\
$\mathrm{R}_{\mathrm{bl}}\left(\mathrm{M} \Omega \mathrm{cm}^{2}\right)$ & - & $16.31 \pm 2.67$ & $11.75 \pm 2.94$ \\
$\left.\mathrm{C}_{\mathrm{bl}}(\mu \mathrm{F} \mathrm{cm})^{-2}\right)$ & - & $2.63 \pm 0.84$ & $1.73 \pm 0.86$ \\
$\mathrm{n}_{\mathrm{bl}}$ & - & $0.84 \pm 0.02$ & $0.86 \pm 0.07$ \\
$\chi^{2}$ & $<1.80 \times 10^{-4}$ & $<7.77 \times 10^{-5}$ & $<1.06 \times 10^{-3}$ \\
\hline
\end{tabular}

time significantly affected the tribocorrosion behaviour. The behaviour of the uncoated samples was observed to be in accordance with the tests made in the same conditions in the literature [65]. The relative increase in the potential up to around $1600 \mathrm{~s}$ during sliding was due to the thickening of the adhered/oxidized patches that may provide a limited protection against corrosion, as also reported by Silva et al. [65] for cpTi (grade 2) tested under similar conditions. After around $1600 \mathrm{~s}$, the thickened adhered/oxidized patches might be removed, thus a decrease was observed on the potential values.

The evolution of OCP and COF was relatively similar on TiN-30 min and uncoated $\mathrm{Ti}$, probably due to the damage of the TiN coating at the beginning of the sliding (indicated by arrows on Fig. 7). After the failure of the coating layer, oxidized patches were formed, and the thickening and breaking of these patches caused increases and decreases both in OCP and COF values. The more positive increments on the OCP values during sliding for TiN-30 min samples compared to uncoated Ti may be due to the incorporation of TiN debris in oxide patches which may provide a relatively higher protection against tribocorrosion. The samples coated with longer deposition time presented a significantly different behaviour as compared to the uncoated and TiN-30 min samples where coating layer was not completely damaged during tribocorrosion thus less negative OCP values were observed, indicating lower tendency to corrosion under sliding.

Adhesive wear is characterized by elevated wear rates and larger, unstable COF resulting with a severe wear damage. During adhesive wear, strong adhesion formed between the asperities of the sliding surfaces causes elevated frictional forces, and the asperities may be removed leading to formation of wear debris, transfer layers, or adhered/oxidized patches. On the other hand, sliding movement leads to plastic deformation of the adhered asperities that may also result on work hardening of the adhered and deformed metallic surfaces eventually resulting in formation of grooves and abrasion scratches on the worn sample surface, which was clearly observed on the worn uncoated Ti and TiN-30 min surfaces (Figs. 8 and 9) [66]. During this action, brittle materials produce less wear debris since they break easier than the ductile materials. As a result, detached pieces from the sample surfaces may attach to the counter material surface (insert on Fig. 10a), may repeatedly move from one sliding surface to the other one, or may attach to the worn sample surface in the form of a transfer film, or adhered/oxidized patch (Figs. 8d-f and 9) being another typical feature of adhesive wear [66] as also reported in the literature for $\mathrm{Ti}[65,67]$ and Ti-6Al-4 V $[47,68]$. Besides, sub-surface cracks mainly observed under the patches on TiN-80 min samples can be related with both the decreased ductility, as well, locally increased contact stresses due to higher roughness. As a result, during reciprocating sliding, fatigue may lead to nucleation and propagation of sub-surfaces cracks on the protruded surfaces [66].

It is known that increasing surface roughness, hardness, and Young's modulus, as well, the presence of contaminants such as oxides and nitrides reduces the influence of adhesive wear [66]. Accordingly, increased hardness, Young's modulus and surface roughness from the uncoated samples to the coated samples resulted with the decreased damage given by adhesive wear to the coated samples, which was confirmed by formation of relatively lesser and shallower adhered/ oxidized patches, sliding grooves (Figs. 8 and 9), and lesser amount of transferred material on the counter material surface (Fig. 10), eventually affecting the material loss during tribocorrosion (Fig. 11). Therefore, TiN-80 min samples having the thickest TiN coating, highest hardness and highest Young's modulus exhibited highest resistance to abrasive wear, maintaining its barrier role between the substrate and the counter material thus minimizing the influence of adhesive wear.

Fig. 12 shows schematically the wear mechanisms proposed for the materials tested in this work. The uncoated and TiN-30 min samples presented mainly a combination of abrasive and adhesive wear governed by parallel grooves, discontinuous tribolayers (patches), plastic deformation, and transferred material, whereas the features of abrasive and adhesive was only occurred on the protruded surfaces on TiN$80 \mathrm{~min}$ samples. However, TiN-80 min samples also suffered to fatigue wear, that was evident on the worn sub-surfaces.

Although this work showed that the deposition time can have a noticeable influence on the tribocorrosion mechanisms, the correlation between the deposition time and tribocorrosion mechanism is worth to be explored more in detail. Besides, since different implants, even in different implant parts over same implants are required different surface characteristics, further studies should consider the effect of the topographical factors, together with the biological factors, on the tribocorrosion mechanisms.

\section{Conclusions}

The corrosion and tribocorrosion behaviour of TiN coating on $\mathrm{cp}-\mathrm{Ti}$ (grade 4) obtained by reactive sputtering with longer deposition time ( $80 \mathrm{~min}$ ) presented lower corrosion rate and better capacitive behaviour due to increased thickness of the coating layer and increased percentage of $\mathrm{Ti}_{2} \mathrm{~N}$ phase on the coating layer. Increased coating thickness and promotion of the formation of $\mathrm{Ti}_{2} \mathrm{~N}$ phase also gave a resistance against abrasive wear, adhesive wear, and plastic (a)

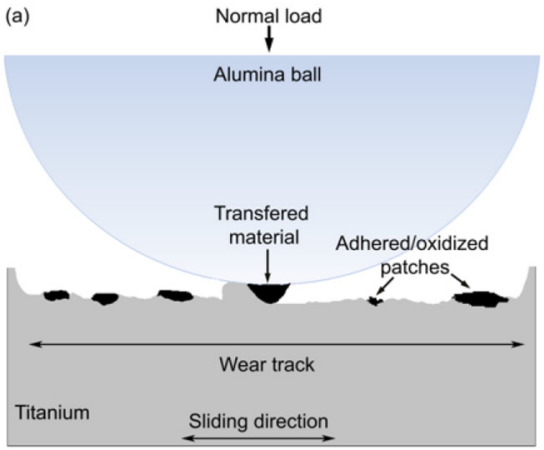

(b)

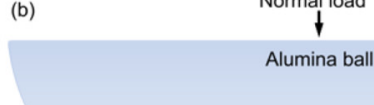

(c) Normal load

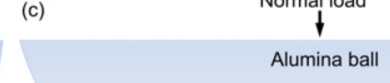

Fig. 12. Schematic tribocorrosion mechanisms of uncoated $\mathrm{Ti}$ (a), TiN-30 min (b) and c) TiN-80 min (c) samples. 
deformation, thus, led to obtain a clear improvement on the tribocorrosion resistance. Therefore, these results pointed that deposition time should be carefully adjusted according to the contact conditions of the targeted applications.

\section{Acknowledgements}

This work is supported by FCT with the reference project UID/EEA/ 04436/2013, COMPETE 2020 with the code POCI-01-0145-FEDER006941, and M-ERA-NET/0001/2015 (FAPESP proc. \#2015/50.280-5) project. I. Caha grateful for financial support through $\mathrm{PhD}$ grant under NORTE-08-5369-FSE-000012 project. The authors would also like to acknowledge Dr. Paulo Ferreira and Dr. Enrique Carbó-Argibay (International Iberian Nanotechnology Laboratory) for the provision of FIB facilities, and Prof. Graça Minas (Universidade do Minho) for the provision of profilometry.

\section{References}

[1] I.V. Okulov, H. Wendrock, A.S. Volegov, H. Attar, U. Kühn, W. Skrotzki, J. Eckert, High strength beta titanium alloys: new design approach, Mater. Sci. Eng. A 628 (2015) 297-302, https://doi.org/10.1016/j.msea.2015.01.073.

[2] Q. Wang, Q. Li, X. Li, R. Zhang, X. Gao, C. Dong, P.K. Liaw, Microstructures and stability origins of $\beta$-(Ti,Zr)-(Mo,Sn)-Nb alloys with low Young's Modulus, Metall. Mater. Trans. A Phys. Metall. Mater. Sci. 46 (2015) 3924-3931, https://doi.org/10. 1007/s11661-015-3011-4.

[3] D.W. Shoesmith, J.J. Noël, Corrosion of titanium and its alloys, Shreir's Corros, 2010, pp. 2042-2052, , https://doi.org/10.1016/B978-044452787-5.00097-4.

[4] M. Niinomi, Biologically and mechanically biocompatible titanium alloys, Mater. Trans. 49 (2008) 2170-2178, https://doi.org/10.2320/matertrans.L-MRA2008828.

[5] M.J. Runa, M.T. Mathew, L.A. Rocha, Tribocorrosion response of the Ti6Al4V alloys commonly used in femoral stems, Tribol. Int. 68 (2013) 85-93, https://doi.org/10. 1016/j.triboint.2013.09.022.

[6] A. Samanta, M. Bhattacharya, I. Ratha, H. Chakraborty, S. Datta, J. Ghosh, S. Bysakh, M. Sreemany, R. Rane, A. Joseph, S. Mukherjee, B. Kundu, M. Das, A.K. Mukhopadhyay, Nano- and micro-tribological behaviours of plasma nitrided Ti6Al4V alloys, J. Mech. Behav. Biomed. Mater. 77 (2018) 267-294, https://doi. org/10.1016/j.jmbbm.2017.09.013.

[7] E. Arslan, Y. Totik, I. Efeoglu, The investigation of the tribocorrosion properties of DLC coatings deposited on Ti6Al4V alloys by CFUBMS, Prog. Org. Coat. (2012) 768-771, https://doi.org/10.1016/j.porgcoat.2011.10.023.

[8] S. Wang, Y. Liu, C. Zhang, Z. Liao, W. Liu, The improvement of wettability, biotribological behavior and corrosion resistance of titanium alloy pretreated by thermal oxidation, Tribol. Int. 79 (2014) 174-182, https://doi.org/10.1016/j. triboint.2014.06.008.

[9] J. Geringer, N. Demanget, J. Pellier, From acid etching treatments to tribocorrosive properties of dental implants: do some experimental results on surface treatments have an influence on the tribocorrosion behaviour of dental implants? J. Phys. D. Appl. Phys. 46 (2013), https://doi.org/10.1088/0022-3727/46/40/404005.

[10] M. Azzi, J.A. Szpunar, Tribo-electrochemical technique for studying tribocorrosion behavior of biomaterials, Biomol. Eng. 24 (2007) 443-446, https://doi.org/10. 1016/j.bioeng.2007.07.015.

[11] M. Annunziata, A. Oliva, M.A. Basile, M. Giordano, N. Mazzola, A. Rizzo, A. Lanza, L. Guida, The effects of titanium nitride-coating on the topographic and biological features of TPS implant surfaces, J. Dent. 39 (2011) 720-728, https://doi.org/10. 1016/j.jdent.2011.08.003.

[12] S. Sathish, M. Geetha, N.D. Pandey, C. Richard, R. Asokamani, Studies on the corrosion and wear behavior of the laser nitrided biomedical titanium and its alloys, Mater. Sci. Eng. C. 30 (2010) 376-382, https://doi.org/10.1016/j.msec.2009.12. 004.

[13] A. Scarano, M. Piattelli, G. Vrespa, G. Petrone, G. Iezzi, A. Piattelli, Bone healing around titanium and titanium nitride-coated dental implants with three surfaces: an experimental study in rats, Clin. Implant. Dent. Relat. Res. 5 (2003) 103-111 http://www.ncbi.nlm.nih.gov/pubmed/14536045.

[14] J.A. Hendry, R.M. Pilliar, The fretting corrosion resistance of PVD surface-modified orthopedic implant alloys, J. Biomed. Mater. Res. 58 (2001) 156-166, https://doi. org/10.1002/1097-4636(2001)58:2<156::AID-JBM1002>3.0.CO;2-H.

[15] J. Bolton, X. Hu, In vitro corrosion testing of PVD coatings applied to a surgical grade Co-Cr-Mo alloy, J. Mater. Sci. Mater. Med. 13 (2002) 567-574, https://doi org/10.1023/A:1015126810485.

[16] J. Zhao, X.M. Cai, H.Q. Tang, T. Liu, H.Q. Gu, R.Z. Cui, Bactericidal and biocompatible properties of TiN/Ag multilayered films by ion beam assisted deposition, J. Mater. Sci. Mater. Med. (2009), https://doi.org/10.1007/s10856-0083491-5.

[17] G.K. Hyde, S.D. McCullen, S. Jeon, S.M. Stewart, H. Jeon, E.G. Loboa, G.N. Parsons, Atomic layer deposition and biocompatibility of titanium nitride nano-coatings on cellulose fiber substrates, Biomed. Mater. 4 (2009) 025001, , https://doi.org/10. 1088/1748-6041/4/2/025001.

[18] Y.S. Al Jabbari, J. Fehrman, A.C. Barnes, A.M. Zapf, S. Zinelis, D.W. Berzins, Titanium nitride and nitrogen ion implanted coated dental materials, Coatings 2
(2012) 160-178, https://doi.org/10.3390/coatings2030160.

[19] S. Piscanec, L.C. Ciacchi, E. Vesselli, G. Comelli, O. Sbaizero, S. Meriani, A. De Vita, Bioactivity of TiN-coated titanium implants, Acta Mater. 52 (2004) 1237-1245, https://doi.org/10.1016/j.actamat.2003.11.020

[20] M.A. Pellman, Co-based alloys, ASTM Spec. Tech. Publ. (1999) 169-178, https:// doi.org/10.1520/Stp14272s.

[21] D.-C. Sin, H.-L. Kei, X. Miao, Surface coatings for ventricular assist devices, Expert Rev. Med. Devices 6 (2009) 51-60, https://doi.org/10.1586/17434440.6.1.51.

[22] F. Galliano, E. Galvanetto, S. Mischler, D. Landolt, Tribocorrosion behavior of plasma nitrided Ti-6Al-4V alloy in neutral $\mathrm{NaCl}$ solution, Surf. Coat. Technol. 145 (2001) 121-131, https://doi.org/10.1016/S0257-8972(01)01309-3.

[23] A.C. Fernandes, F. Vaz, E. Ariza, L.A. Rocha, A.R.L. Ribeiro, A.C. Vieira, J.P. Rivière, L. Pichon, Tribocorrosion behaviour of plasma nitrided and plasma nitrided + oxidised Ti6Al4V alloy, Surf. Coat. Technol. 200 (2006) 6218-6224, https://doi. org/10.1016/j.surfcoat.2005.11.069.

[24] T.M. Manhabosco, S.M. Tamborim, C.B. dos Santos, I.L. Müller, Tribological, elec trochemical and tribo-electrochemical characterization of bare and nitrided Ti6Al4V in simulated body fluid solution, Corros. Sci. 53 (2011) 1786-1793, https://doi.org/10.1016/j.corsci.2011.01.057.

[25] X. Zhao, P. Zhang, X. Wang, Y. Chen, H. Liu, L. Chen, Y. Sheng, W. Li, In-situ formation of textured TiN coatings on biomedical titanium alloy by laser irradiation, J. Mech. Behav. Biomed. Mater. 78 (2018) 143-153, https://doi.org/10.1016/ j.jmbbm.2017.11.019.

[26] Ç. Albayrak, I. Hacisalihoğlu, S. Yenal vangölü, A. Alsaran, Tribocorrosion behavior of duplex treated pure titanium in simulated body fluid, Wear 302 (2013) 1642-1648, https://doi.org/10.1016/j.wear.2013.01.064.

[27] G.H. Zhao, R.E. Aune, N. Espallargas, Tribocorrosion studies of metallic biomaterials: the effect of plasma nitriding and DLC surface modifications, J. Mech. Behav. Biomed. Mater. 63 (2016) 100-114, https://doi.org/10.1016/j.jmbbm.2016.06. 014.

[28] A. Shenhar, I. Gotman, S. Radin, P. Ducheyne, E.Y. Gutmanas, Titanium nitride coatings on surgical titanium alloys produced by a powder immersion reaction assisted coating method: residual stresses and fretting behavior, Surf. Coat. Technol. 126 (2000) 210-218, https://doi.org/10.1016/S0257-8972(00)00524-7.

[29] M. Rizwan, A. Ahmad, K.M. Deen, W. Haider, Electrochemical behavior and biological response of mesenchymal stem cells on cp-Ti after $\mathrm{N}$-ions implantation, Appl. Surf. Sci. 320 (2014) 718-724, https://doi.org/10.1016/j.apsusc.2014.09. 169.

[30] G.S. Savonov, M. Ueda, R.M. Oliveira, C. Otani, Electrochemical behavior of the Ti6Al4V alloy implanted by nitrogen PIII, Surf. Coat. Technol. 206 (2011) 2017-2020, https://doi.org/10.1016/j.surfcoat.2011.09.007.

[31] F.M. El-Hossary, N.Z. Negm, A.M. Abd El-Rahman, M. Raaif, A.A. Seleem, A.A. Abd El-Moula, Tribo-mechanical and electrochemical properties of plasma nitriding titanium, Surf. Coat. Technol. 276 (2015) 658-667, https://doi.org/10.1016/j. surfcoat.2015.06.003.

[32] I.M. Pohrelyuk, V.M. Fedirko, O.V. Tkachuk, R.V. Proskurnyak, Corrosion resistance of Ti-6Al-4V alloy with nitride coatings in Ringer's solution, Corros. Sci. 66 (2013) 392-398, https://doi.org/10.1016/j.corsci.2012.10.005.

[33] C. Mendoza, Z. Gonzalez, E. Gordo, B. Ferrari, Y. Castro, Protective nature of nanoTiN coatings shaped by EPD on Ti substrates, J. Eur. Ceram. Soc. 38 (2017) 495-500, https://doi.org/10.1016/j.jeurceramsoc.2017.09.046.

[34] E. Galvanetto, F.P. Galliano, A. Fossati, F. Borgioli, S. Marta, Corrosion Resistance Properties of Plasma Nitrided Ti - 6Al - 4V Alloy in Hydrochloric Acid Solutions, vol. 44, (2002), pp. 1593-1606.

[35] A. Fossati, F. Borgioli, E. Galvanetto, T. Bacci, Corrosion resistance properties of plasma nitrided Ti-6Al-4V alloy in nitric acid solutions, Corros. Sci. 46 (2004) 917-927, https://doi.org/10.1016/S0010-938X(03)00188-4.

[36] F. Yildiz, A.F. Yetim, A. Alsaran, A. Celik, Plasma nitriding behavior of Ti6Al4V orthopedic alloy, Surf. Coat. Technol. 202 (2008) 2471-2476, https://doi.org/10. 1016/j.surfcoat.2007.08.004.

[37] T. Wierzchoń, E. Czarnowska, J. Grzonka, A. Sowińska, M. Tarnowski, J. Kamiński, K. Kulikowski, T. Borowski, K.J. Kurzydłowski, Glow discharge assisted oxynitriding process of titanium for medical application, Appl. Surf. Sci. 334 (2015) 74-79, https://doi.org/10.1016/j.apsusc.2014.08.071.

[38] V. Fouquet, L. Pichon, M. Drouet, A. Straboni, Plasma assisted nitridation of Ti-6Al4V, Appl. Surf. Sci. 221 (2004) 248-258, https://doi.org/10.1016/S0169-4332(03) 00889-4.

[39] D. Nolan, S.W. Huang, V. Leskovsek, S. Braun, Sliding wear of titanium nitride thin films deposited on Ti-6Al-4V alloy by PVD and plasma nitriding processes, Surf. Coat. Technol. 200 (2006) 5698-5705, https://doi.org/10.1016/j.surfcoat.2005. 08.110 .

[40] D. Goldbaum, P. Manimuda, G. Kamath, S. Descartes, J.E. Klemberg-Sapieha, R.R. Chromik, Tribological behavior of TiN and Ti $(\mathrm{Si}, \mathrm{C}) \mathrm{N}$ coatings on cold sprayed Ti substrates, Surf. Coat. Technol. 291 (2016) 264-275, https://doi.org/10.1016/j. surfcoat.2016.02.044.

[41] J. Wagner, V. Edlmayr, M. Penoy, C. Michotte, C. Mitterer, M. Kathrein, Deposition of Ti-Al-N coatings by thermal CVD, Int. J. Refract. Met. Hard Mater. 26 (2008) 563-568, https://doi.org/10.1016/j.ijrmhm.2008.01.003.

[42] J. Bohlmark, M. Östbye, M. Lattemann, H. Ljungcrantz, T. Rosell, U. Helmersson, Guiding the deposition flux in an ionized magnetron discharge, Thin Solid Films 515 (2006) 1928-1931, https://doi.org/10.1016/j.tsf.2006.07.183.

[43] S.G. Harris, E.D. Doyle, Y.C. Wong, P.R. Munroe, J.M. Cairney, J.M. Long, Reducing the macroparticle content of cathodic arc evaporated TiN coatings, Surf. Coat. Technol. 183 (2004) 283-294, https://doi.org/10.1016/j.surfcoat.2003.08.086.

[44] G.A. Rodríguez-Castro, L.F. Jiménez-Tinoco, J.V. Méndez-Méndez, I. ArzateVázquez, A. Meneses-Amador, H. Martínez-Gutiérrez, I. Campos-Silva, Damage 
mechanisms in AISI 304 Borided steel: scratch and Daimler-Benz adhesion tests, Mater. Res. 18 (2015) 1346-1353, https://doi.org/10.1590/1516-1439.025515.

[45] E. Gemelli, A. Scariot, N.H.A. Camargo, Thermal characterization of commercially pure titanium for dental applications, Mater. Res. 10 (2007) 241-246, https://doi. org/10.1590/s1516-14392007000300004.

[46] H. Ollendorf, D. Schneider, A comparative study of adhesion test methods for hard coatings, Surf. Coat. Technol. 113 (1999) 86-102, https://doi.org/10.1016/S02578972(98)00827-5.

[47] Z. Doni, A.C. Alves, F. Toptan, J.R. Gomes, A. Ramalho, M. Buciumeanu, L. Palaghian, F.S. Silva, Dry sliding and tribocorrosion behaviour of hot pressed CoCrMo biomedical alloy as compared with the cast CoCrMo and Ti6Al4V alloys, Mater. Des. 52 (2013) 47-57, https://doi.org/10.1016/j.matdes.2013.05.032.

[48] V. Poulek, J. Musil, V. Valvoda, R. Černý, Microhardness of Ti-N films containing the $\varepsilon$-Ti2N phase, J. Phys. D. Appl. Phys. 21 (1988), https://doi.org/10.1088/ 0022-3727/21/11/020.

[49] I. Petrov, P.B. Barna, L. Hultman, J.E. Greene, Microstructural evolution during film growth, J. Vac. Sci. Technol. A Vacuum, Surfaces, Film. (2003), https://doi.org/10. 1116/1.1601610.

[50] N.K. Ponon, D.J.R. Appleby, E. Arac, P.J. King, S. Ganti, K.S.K. Kwa, A. O'Neill, Effect of deposition conditions and post deposition anneal on reactively sputtered titanium nitride thin films, Thin Solid Films 578 (2015) 31-37, https://doi.org/10. 1016/j.tsf.2015.02.009.

[51] E. Broitman, L. Hultman, Adhesion improvement of carbon-based coatings through a high ionization deposition technique, J. Phys. Conf. Ser. 370 (2012), https://doi. org/10.1088/1742-6596/370/1/012009.

[52] N. Figueira, T.M. Silva, M.J. Carmezim, J.C.S. Fernandes, Corrosion behaviour of NiTi alloy, Electrochim. Acta 54 (2009) 921-926, https://doi.org/10.1016/j. electacta.2008.08.001.

[53] M.E. Orazem, B. Tribollet, Electrochemical Impedance Spectroscopy, Jonh Wiley \& Sons, New Jersey, 2008.

[54] N. Diomidis, S. Mischler, N.S. More, M. Roy, Tribo-electrochemical characterization of metallic biomaterials for total joint replacement, Acta Biomater. 8 (2012) 852-859, https://doi.org/10.1016/j.actbio.2011.09.034.

[55] E.L. Rooy, J.H.L. Van Linden, ASM Metals Handbook, Properties and Selection: Nonferrous Alloys and Special-Purpose Materials, Metals Park, Ohio, vol 02, 1990, https://doi.org/10.1016/S0026-0576(03)90166-8.

[56] A. Iwabuchi, J.W. Lee, M. Uchidate, Synergistic effect of fretting wear and sliding wear of Co-alloy and Ti-alloy in Hanks' solution, Wear 263 (2007) 492-500, https://doi.org/10.1016/j.wear.2007.01.102.

[57] S. Yu, Q. Zeng, A.R. Oganov, G. Frapper, L. Zhang, Phase stability, chemical bonding and mechanical properties of titanium nitrides: a first-principles study,
Phys. Chem. Chem. Phys. 17 (2015) 11763-11769, https://doi.org/10.1039/ c5cp00156k.

[58] R.P. Van Hove, I.N. Sierevelt, B.J. Van Royen, P.A. Nolte, Titanium-nitride coating of orthopaedic implants: a review of the literature, Biomed. Res. Int. 2015 (2015), https://doi.org/10.1155/2015/485975.

[59] H. Aghajani, M.S. Motlagh, Effect of temperature on surface characteristics of nitrogen ion implanted biocompatible titanium, J. Mater. Sci. Mater. Med. 28 (2017) 29, , https://doi.org/10.1007/s10856-016-5843-x.

[60] A. Scerri, J. Buhagiar, S. Banfield, J.C. Avelar-Batista Wilson, J. Housden, A. Leyland, A. Matthews, G. Cassar, Corrosion behaviour of triode plasma diffusion treated and PVD TiN-coated Ti-6Al-4V in acidified aqueous chloride environments, Surf. Coat. Technol. 280 (2015) 185-193, https://doi.org/10.1016/j.surfcoat.2015. 08.040 .

[61] L. Thair, U.K. Mudali, N. Bhuvaneswaran, K.G.M. Nair, R. Asokamani, B. Raj, Nitrogen ion implantation and in vitro corrosion behavior of as-cast Ti-6Al-7Nb alloy, Corros. Sci. 44 (2002) 2439-2457, https://doi.org/10.1016/S0010-938X(02) 00034-3.

[62] S.I. Drob, C. Vasilescu, P. Drob, E. Vasilescu, D.M. Gordin, T. Gloriant, Corrosion behaviour of nitrogen-implantation Ti-Ta-Nb alloy in physiological solutions simulating real conditions from human body, Jom 67 (2015) 818-829, https://doi. org/10.1007/s11837-015-1351-6.

[63] D. Zhou, H. Liang, S. Chu, J. Xu, Y. Bai, X. Sun, Thickness dependent microstructural and electrical properties of TiN thin films prepared by DC reactive magnetron sputtering, Ceram. Int. 42 (2015) 2642-2647, https://doi.org/10.1016/ j.ceramint.2015.10.070.

[64] N. Heide, J.W. Schultze, Corrosion stability of TiN prepared by ion implantation and PVD, Nucl. Inst. Methods Phys. Res. B 80-81 (1993) 467-471, https://doi.org/ 10.1016/0168-583X(93)96162-6.

[65] J.I. Silva, A.C. Alves, A.M. Pinto, F. Toptan, Corrosion and tribocorrosion behavior of $\mathrm{Ti}-\mathrm{TiB}-\mathrm{TiNx}$ in-situ hybrid composite synthesized by reactive hot pressing, $\mathrm{J}$. Mech. Behav. Biomed. Mater. 74 (2017) 195-203, https://doi.org/10.1016/j. jmbbm.2017.05.041.

[66] G.W. Stachowiak, A.W. Batchelor, Engineering Tribology, Butterworth Heinemann, 2005.

[67] F. Toptan, A. Rego, A.C. Alves, A. Guedes, Corrosion and tribocorrosion behavior of Ti-B4C composite intended for orthopaedic implants, J. Mech. Behav. Biomed. Mater. 61 (2016) 152-163, https://doi.org/10.1016/j.jmbbm.2016.01.024.

[68] W.H. Kao, Y.L. Su, Y.T. Hsieh, Effects of duplex nitriding and TiN coating treatment on wear resistance, corrosion resistance and biocompatibility of Ti6Al4V alloy, J. Mater. Eng. Perform. 26 (2017) 3686-3697, https://doi.org/10.1007/s11665-0172815-3. 